\title{
COMUNICACÕES
}

\section{Primeiro registro de Cylindrocladium parasiticum em plantas de teca no Pará}

\author{
Luiz Sebastião Poltronieri ${ }^{1}$, Rafael Ferreira Alfenas ${ }^{2}$, Acelino Couto Alfenas ${ }^{2}$, Jaqueline Rosemeire Verzignassi ${ }^{3}$, Ruth \\ Linda Benchimol ${ }^{1}$, Tathianne Pastana de SousaPoltronieri ${ }^{1}$
}

\begin{abstract}
${ }^{1}$ Embrapa Amazônia Oriental, Tv. Enéas Pinheiro, S/N, CEP 66095-100, Belém, PA. 2Departamento de Fitopatologia, Universidade Federal de Viçosa, CEP 36570-000, Viçosa, MG. 3Embrapa Gado de Corte, Rod. BR 262, Km 4, Caixa Postal 154, CEP 79002-970, Campo Grande, MS. Autor para correspondência: Jaqueline Rosemeire Verzignassi (jaqueline@cnpgc.embrapa.br)

Data de chegada: 21/10/2009. Aceito para publicação em: 03/06/2004.
\end{abstract}

Tectona grandis Linn. F., popularmente conhecida como teca, é uma árvore de grande porte, nativa das florestas tropicais. No sul da Ásia, a cultura de teca é tradicional, sendo cultivada em grande escala. Atualmente, a área mundial plantada excede os 3 milhões de hectares, incluindo, além dos asiáticos, que são os maiores produtores, outros países tropicais, como o Togo, Camarões, Zaire, Nigéria, Trinidad, Honduras e Brasil. Apesar de poder ser cultivada apenas em regiões tropicais, a madeira de teca é muito procurada, principalmente no continente europeu, onde o preço por metro cúbico supera o do mogno. Em outubro de 2008 folhas de teca, oriundas de plantio comercial localizado no município de Igarapé-Açu (PA), apresentando manchas de coloração marrom clara, que coalesciam e atingiam grande extensão do limbo foliar foram encaminhadas ao Laboratório de Fitopatologia da Embrapa Amazônia Oriental. Um fungo do gênero Cylindrocladium foi isolado em agar-água e multiplicado para meio de cultura batatadextrose-ágar (BDA). A partir do teste de patogenicidade, realizado em mudas sadias de teca com dois meses de idade, os mesmos sintomas observados em campo foram novamente verificados e o fungo reisolado das plantas inoculadas, confirmando a espécie de Cylindrocladium como o agente causal da doença. Verificou-se, sobre as lesões e meio de cultura, o desenvolvimento de conidióforos penicilióides, contendo vesículas globosas a subglobosas e conídios cilíndricos, hialinos, com um a três septos, medindo 54-78x4, 5-5, 9 $\mu \mathrm{m}$, típicos de Cylindrocladium parasiticum Crous, Wingfield \& Alfenas (Crous et al., Mycol. Res. 97:889-896, 1993), teleomorfo: Calonectria ilicicola Boedijn \& Reitsma. Este é o primeiro registro deste fungo em plantas de teca no Estado do Pará e, aparentemente, no Brasil.

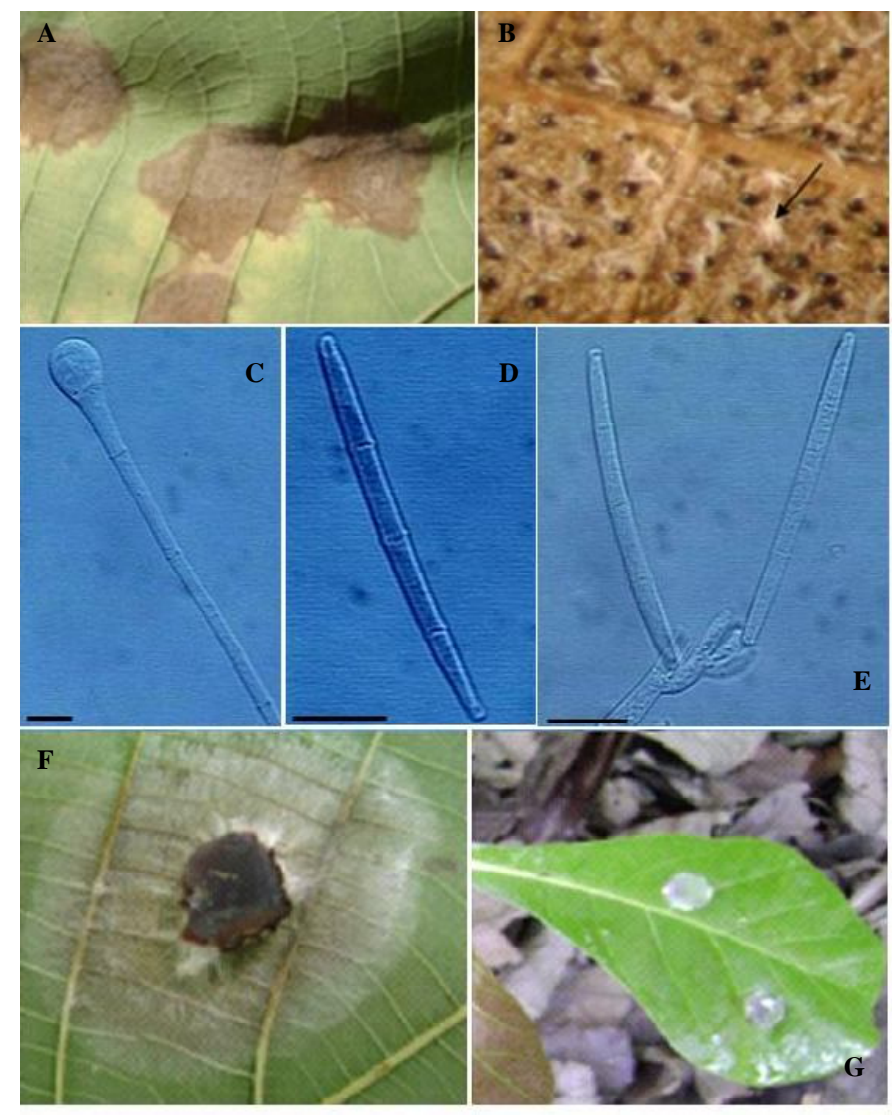

Figura 1. Cylindrocladium parasiticum em teca: mancha foliar causada pelo fungo (A); conidióforos presentes na lesão (B); conidióforo do fungo contendo vesícula típica (C); conídio típico do fungo (D); conidióforo e conídios típicos do fungo (E); teste de patogenicidade - folha inoculada com o fungo $(\mathrm{F})$ e sintomas provocados pelo fungo $(\mathrm{G})$. (Barras na figura $=20 \mu \mathrm{m})$. 